\title{
GOVERNMENT OPENS CONSULTATION ON ENDING MANDATORY VACCINATION
}

At the end of January, the British Dental Association (BDA) welcomed the government's move to open a consultation on ending mandatory vaccination but stressed that collateral damage among the workforce remains likely, given the number of colleagues who have already made plans to leave the service and the uncertainty now facing staff in the weeks ahead.

Under the regulations fast tracked through parliament in December, dental staff in both NHS and private practice risk dismissal if they are not double jabbed by April, leaving 3 February the effective deadline for a first vaccination. Over 1,000 NHS dentists left the service in the last year, and recruitment and retention problems are already endemic among both dentists and the wider dental team.

The service is already facing unprecedented backlogs, with over 38 million NHS dental appointments lost since the first lockdown due to the initial suspension of face-to-face care and ongoing infection control measures.

In response to a BDA survey in December, one in ten high street dentists said they were not fully vaccinated, with $9 \%$ reporting they had not had their first jab. Less than two thirds of respondents believed all dentists operating in their practices were fully vaccinated, with less than half saying their dental nurses, who are integral to the delivery of care, were fully vaccinated. Over $30 \%$ believed dental nurses at their practices would leave as a result of the mandate.

The regulations were subject to a damning report by the House of Lords Secondary Legislation Scrutiny Committee. While an impact assessment was published at the eleventh hour, it simply extrapolated patterns of vaccine hesitancy for primary care dentistry from the wider NHS workforce, and failed to acknowledge the depth of recruitment and retention problems that already exist in the sector. The BDA is aware that internal consultations in many practices began in earnest following the passage of regulations in December, that notices have already been provided by some hesitant staff, and that significant damage has been sustained to working relationships within many closeknit dental teams.
The BDA - like all major healthcare unions - had supported the vaccine programme from the outset, but objected to this policy on the likely impact on workforce sustainability and patient access.

\section{CGDent and BADN}

Days earlier, the College of General Dentistry (CGDent) and the British Association of Dental Nurses (BADN) warned of a potential catastrophe for dental patients it the planned implementation of mandatory COVID-19 for all patient-facing staff in England was not deferred.

Both CGDent and BADN are unequivocal in their encouragement of dental professionals to take up the offer of coronavirus vaccination. However, interim results from the BADN COVID Vaccination Survey, based on the responses of over 1,000 practising dental nurses up until 27 January, showed that $26 \%$ had not yet received two vaccination doses, and $24 \%$ would not have been doublevaccinated by the deadline.

If the findings are representative of the dental nursing profession as a whole which makes up half the dental workforce this would suggest an impending reduction in available dental staff in England of up to 12,000 , or $12 \%$, plus any dentists, dental therapists, dental hygienists, clinical dental technicians or orthodontic therapists who may not be double-vaccinated.

At the announcement of the U-turn on mandatory vaccination, BDA Chair Eddie Crouch said: 'What we needed today was a clean break; instead colleagues now face confusion, and real uncertainty as to where they stand in the days and weeks ahead.

'Mandatory vaccination offers a lesson in how not to make laws. MPs and Peers rightly decried the impossibility of scrutinising fast-tracked legislation based on back-of-an-envelope calculations. This service was already haemorrhaging talent, and these rules would have pushed many dental practices over the edge.

'The late return of common sense means millions of patients may still dodge a bullet. However, it remains to be seen how many notices have already been handed in, and what the impact will be on the thousands already reconsidering their futures.'

\section{ORAL HEALTH ANIMATION UNVEILED AHEAD OF CHINESE NEWYEAR}

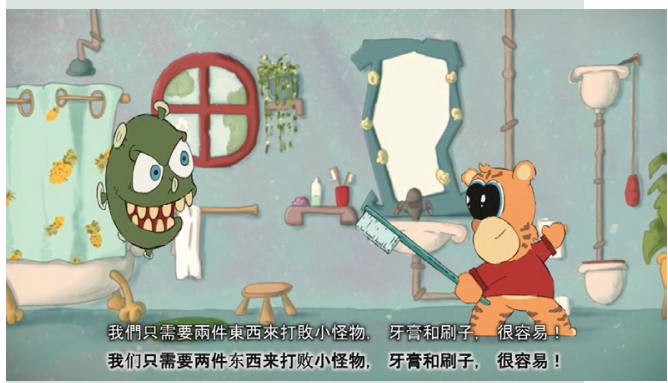

An animation promoting good oral hygiene for children was unveiled by Lanarkshire Chinese Association (LCA) ahead of the Chinese New Year.

New College Lanarkshire graduate Ruben Fernandez created the film designed to encourage regular tooth brushing and healthy eating choices. He was commissioned by LCA while a student of HND 3D Computer Animation at the College's Motherwell Campus.

The three-minute-long animation had its debut at the bowling pavilion of Hamilton Palace Sports Ground as part of the LCA's Annual General Meeting and Chinese New Year celebrations.

The film features a tiger cub character conceptualised by Ruben to reflect the fact that 2022 is the Year of the Tiger in the Chinese Zodiac.

Ruben, who is originally from Spain and now lives in Blantyre, said: 'I felt so good when I finished the project and seeing that the Association love the final product is a bonus point!

Lecturer Scott McKenzie, HND 3D Computer Animation Course Leader, said: 'Ruben Fernandez's stunningly-professional animated short will help to improve the quality of life and wellbeing of children of Lanarkshire's Chinese community.

'Ruben's educational animation promotes oral health and hygiene in a manner that is humorous, attractive to a young audience, and beautifully executed.

The project is funded by the Scottish Government through its Oral Health Community Challenge Fund, which is providing $£ 35,810$ over three years to improve oral health amongst infants and families in the Chinese community in Lanarkshire.

To watch the animation, visit: https://www.youtube.com/ watch?v=S9PeJEMc1mE\&feature=youtu.be . 